\title{
Maternal Mental Health and Risk of Children Diarrhea and Acute Respiratory Infection in Indonesia
}

\author{
Diah Yunitawati ${ }^{1}$, Yusi Dwi Nurcahyani ${ }^{2}$, Leny Latifah ${ }^{3}$, Prihatin Broto Sukandar ${ }^{4}$ \\ \{itadiah@yahoo.com ${ }^{1}$ \} \\ Health Research and Development Center Magelang, Ministry of Health, 46553, Indonesia ${ }^{1,2,3,4}$
}

\begin{abstract}
There are between 4.4 and 3.6\% of the world's population who experience depression and anxiety. Data on Basic Health Research shows that the proportion of Indonesian people suffering from emotional mental disorders fell from 11.6 to $6 \%$ in 2013. Maternal mental health can affect children's growth and development. The purpose is to investigate the relationship between maternal mental health and the risk of children's diarrhea and ARI in Indonesia. Data comes from the Indonesian Basic Health Research in 2013. The analyzed variables using logistic regression are the history of acute respiratory infection (ARI) and diarrhea, child and maternal characteristics. The prevalence of high common mental disorders (CMD) is $4.6 \%$. ARI has a higher incidence compared to the incidence of diarrhea ( $40.6 \%$ and $11.9 \%)$. The analysis shows that maternal CMD is related to ARI history $(\mathrm{OR}=2.12 ; 95 \% \mathrm{CI}: 1.87-2.40)$ and diarrhea history $(\mathrm{OR}=2.36 ; 95 \% \mathrm{CI}$ : 2.03-2.74). Maternal CMD is associated with the incidence of child illness and increases the risk of ARI and diarrhea. Implication. The intervention to increase the maternal mental health status needs to get more attention because it contributes to the child's health status.
\end{abstract}

Keywords: ARI, children, diarrhea, mental health

\section{Introduction}

Mental health is an inseparable part from health problem corresponding to what is written in the Constitution of WHO stating that health is a complete physical, mental and social condition, not only because there is no certain diseases or weaknesses. Women are one of the vulnerable groups to mental disorder problems caused by the household problem, poverty, too much work, and stress [1]. According to the data from WHO, most of the mental disorders are anxiety and depression. Estimated that $4.4 \%$ of the world population suffers from depression and around 3.6\% get anxiety. Besides that, more than $80 \%$ of this disorder is experienced by people living in low and middle-income countries [2]. The data from Basic Health Research 2007 states that the proportion of Indonesian people suffering from an emotional mental disorder is $11.6 \%$ and level down in 2013 which is $6 \%$. Based on those two surveys, the percentage of emotional mental disorders is higher suffered by women [3].

The theoretical framework regarding parenting and its impact on children from UNICEF states that maternal characteristics are one of the factors that can influence the growth, development, and survival of children. These maternal characteristics are related to physical and mental health problems, education, employment, and knowledge about nutrition issues [4]. The maternal mental health, in this case, is stress or in the more severe level called depression will affect how the parenting is done. Some researches state that mothers with depressive symptoms compared to those who are not will bring up certain problems to the children [5]-[7]. The 
positive mother's feelings will increase her feeling and responsibility to her children, so she can realize what ability they have, give them support and help to learn new things [8]. On another side, poor maternal mental health will relate to the problem of breastfeeding and feeding practice that is not optimal and decrease the interaction between mothers and children [9-10].

Research in Bangladesh and Vietnam showed that mental disorder problem in mothers will relate to the children's stunting and underweight. Moreover, it was related to their health [11]. The data on children's nutritional status in Indonesia has changed for five years. The proportion of under-five children suffering underweight in 2007 was $18.4 \%$ and slightly increased in 2013 to $19.6 \%$. While the proportion of toddlers suffered from wasting in 2007 was $13.6 \%$, and it decreased by $12.1 \%$ in 2013 [3]. The most frequent diseases experienced by a child and includes the global main factor of childhood mortality are respiratory tract infection and diarrhea [12]. Based on the Riskesdas result, diarrhea in under-five children according to the health workers diagnosis which was $2.2 \%$ and $3.5 \%$ with the most common symptom as the diagnoses (in 2013). It has decreased than in 2007 which was $5.1 \%$ and $9 \%$. The proportion of ARI for all ages in 2007 was $8.1 \%$ (based on the health workers diagnose) and $25.5 \%$ (based on ARI symptom) and there were $13.8 \%$ and $25 \%$ in 2013 [3].

Based on the explanation before, the relationship between maternal emotional mental disorder and children's health history in Indonesia should be determined.

\section{Method}

The source of data was taken from the 2013 Indonesian Basic Health Survey (Riskesdas). Riskesdas was a national-scale survey conducted in a cross-sectional by the Ministry of Health. Riskesdas sample was carried out by multistage cluster random sampling. The stages of this method were described as follows: The first step was to select the primary sampling unit (PSU) from the systematically selected PSU for each district/city according to the domain location. In the second stage, from the selected PSU, 2 census blocks were selected by probability proportional to size with the number of households in the 2010 Population Census. Then one block was randomly selected for Riskesdas and one census block for Susenas. In the third stage, from each census block of Riskesdas, several census buildings were selected systematically based on the 2010 Population Census building data.

The population and sample in this paper were the households having children (0-59 months) in all Indonesian regions. The samples analyzed were 78,000 respondents. The variables in this article were the maternal characteristics including age, education, common mental disorder; child characteristics include age, gender, health status (the records of ARI and diarrhea); family economic status.

The status of child health was seen based on the disease history experienced by the child. Acute respiratory infection history in this study was measured by the interview result done to mother and children about whether their children have been diagnosed with ARI in the past month and or they have suffered fever and cough with phlegm, dry cough, or flu in the past month before the interview session. A child's history of diarrhea was defined based on the health workers' diagnose and or the symptom experienced by the child such as defecate for more than 3 times a day in the last 2 weeks before the survey.

Emotional mental disorder status was the condition that indicated an individual experiencing a psychological change that can recover as before or become more serious problems if it was not overcome. In this study, it was measured by the Self Reporting 
Questionnaire (SRQ) consist of 20 questions. It has answer options of "yes" and "no" and scored 1 and 0 . It measures some symptoms of depression obtained by showing the higher levels of emotional mental disorders. In this study, the cut-off value of 7 is used, if the subject has a value of at least 7, meaning that it is indicated experiencing mental-emotional disorders [11].

The descriptive statistics for all the variables were calculated. Bivariate analysis was done to analyze the relationship between maternal CMD and child illness. Logistic regression analysis was done to determine the relationship between maternal CMD and maternal characteristics. Processing data using the help of SPSS v. 21 software.

The 2013 Riskesdas has an ethical permit approved by the national ethical committee (ethic number: 01.1206.207). During data collection, informed consent was used. This is by considering the aspects of procedures for data collection, voluntary, and confidentiality.

\section{Results and Discussion}

\subsection{Results}

Table 1 shows the prevalence of ARI, diarrhea, and pneumonia suffered by the children, the mental health problem experienced by the mother, also describes the distribution from other variables.

Table 1. Characteristics of The Study Population

\begin{tabular}{cr}
\hline \multicolumn{1}{c}{ Variables } & $\mathbf{N = 7 8 , 0 0 0}(\mathbf{\%})$ \\
\hline Dependent variables & \\
ARI (symptom and diagnosis) & $31,646(40.6)$ \\
Diarrhea (symptom and diagnosis) & $9,296(11.9)$ \\
\hline Independent variables & \\
Maternal characteristics & $1.2 \pm 2.36$ \\
CMD, mean \pm SD, & $3,589(4.6)$ \\
High CMD $(\geq 7)$ & $74,411(95.4)$ \\
Low CMD $(<7)$ & $31.3 \pm 6.32$ \\
Mother's age, year (mean \pm SD) & $107 \quad(0.1)$ \\
$<16$ years & $19,280(24.7)$ \\
$16-25$ years & $42,585(54.6)$ \\
$26-35$ years & $15,297(19.6)$ \\
36 -45 years & $731(0.9)$ \\
$>45$ years & \\
Mother education, N (\%) & $7,593(9.7)$ \\
No education & $22,218(28.5)$ \\
Elementary school & $19,202(24.6)$ \\
Junior high school & $22,614(29.0)$ \\
Senior high school & $6,373(8.2)$ \\
Diploma or above & \\
Family economic status & $11,696(15.0)$ \\
Quintile 1 &
\end{tabular}




\begin{tabular}{|c|c|}
\hline Variables & $\mathrm{N}=78,000(\%)$ \\
\hline Quintile 2 & $14,022(18.0)$ \\
\hline Quintile 3 & $16,678(21.4)$ \\
\hline Quintile 4 & $19,558(25.1)$ \\
\hline Quintile 5 & $16,046(20.6)$ \\
\hline \multicolumn{2}{|l|}{ Child characteristics } \\
\hline Child age, month (mean \pm SD) & $30.6 \pm 17.31$ \\
\hline$<1$ month & $1,176(1.5)$ \\
\hline $1-11$ months & $13,820(17.7)$ \\
\hline $12-23$ months & 15,507 (19.9) \\
\hline $24-35$ months & $15,065(19.3)$ \\
\hline$>35$ months & $32,432(41.6)$ \\
\hline \multicolumn{2}{|l|}{$\operatorname{Sex}(N, \%)$} \\
\hline Male & $39,559(50.7)$ \\
\hline Female & $38,441(49.3)$ \\
\hline
\end{tabular}

As stated in Table 1 above, the frequency of children suffering ARI is $40.6 \%$, diarrhea is $11.9 \%$, and pneumonia is $4 \%$. The prevalence of mothers with a high mental health problem is $4.6 \%$. Most of the mother is in a safe reproductive age which is $26-35$ years old and there is almost $1 \%$ mother ages 45 years old. The percentage of mothers' education is almost the same among those who have completed primary school, graduated from junior high school, and graduated from senior high school. The percentage of middle and upper economic status is $25 \%$ and the lowest percentage is in the lowest quintile of $15 \%$. The proportion of children who were the subjects of the study was almost half the age between 3-5 years and the number of boys and girls was almost the same.

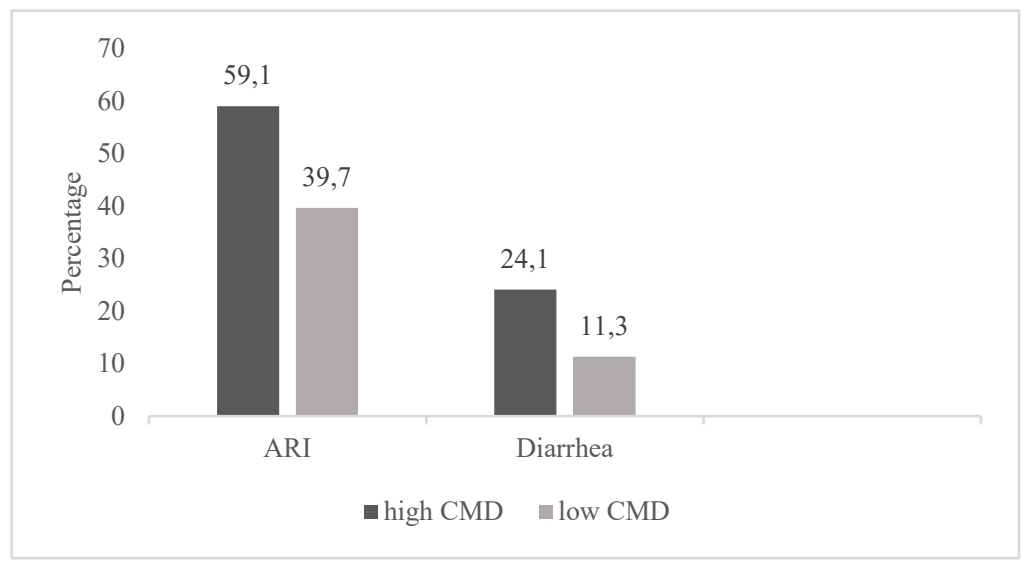

Fig 1. Relationship between maternal CMD and the children with ARI, diarrhea and pneumonia

The prevalence of a child's illness history based on the maternal CMD condition can be seen in Figure 1. If we see from the comparison between children with low CMD mothers, then children with high CMD mothers have a higher proportion of child's illness in all diseases which are ARI, diarrhea, and pneumonia. 
Table 2. Relationship of maternal and child characteristics according to ARI

\begin{tabular}{|c|c|c|c|}
\hline \multirow{2}{*}{$\begin{array}{l}\text { Maternal and child characteristics } \\
\qquad(\mathrm{N}=\mathbf{7 8 , 0 0 0 )}\end{array}$} & \multicolumn{3}{|c|}{ ARI } \\
\hline & Prevalence N (\%) & OR $(95 \% \text { CI })^{a}$ & OR $(95 \% \text { CI })^{b}$ adjusted \\
\hline \multicolumn{4}{|l|}{ Maternal CMD } \\
\hline High CMD $(\geq 7)(n=3,589)$ & $2,120(59.1)$ & $2.08(1.94-2.24)^{*}$ & $2.12(1.87-2.40)^{*}$ \\
\hline Low $\operatorname{CMD}(<7)(\mathrm{n}=74,411)$ ref & $29,526(39.7)$ & & \\
\hline \multicolumn{4}{|l|}{ Maternal age } \\
\hline$<16$ years $(\mathrm{n}=107)$ & $49(45.8)$ & $1.25(0.68-2.31)$ & $1.41(0.75-2.67)$ \\
\hline $16-25$ years $(\mathrm{n}=19,280)$ & $8,420(43.7)$ & $1.18(1.12-1.25)^{*}$ & $1.30(1.04-1.62)^{*}$ \\
\hline $26-35$ years $(\mathrm{n}=42,585)$ & $17,039(40.0)$ & $0.95(0.91-0.99)^{*}$ & $1.14(0.92-1.42)$ \\
\hline $36-45$ years $(n=15,297)$ & $5,860(38.3)$ & $0.89(0.85-0.94)^{*}$ & $1.04(0.83-1.30)$ \\
\hline$>45$ years $(\mathrm{n}=731)$ & $277(37.9)$ & $0.89(0.72-1.11)$ & \\
\hline \multicolumn{4}{|l|}{ Maternal education } \\
\hline No education $(\mathrm{n}=7,593)$ & $3,303(43.5)$ & $1.14(1.06-1.23)^{*}$ & $1.35(1.21-1.51)^{*}$ \\
\hline Primary school $(\mathrm{n}=22,218)$ & $9,447(42.5)$ & $1.12(1.06-1.18)^{*}$ & $1.31(1.19-1.44)^{*}$ \\
\hline Junior high school $(\mathrm{n}=19,202)$ & $7,969(41.5)$ & $1.05(0.99-1.11)$ & $1.24(1.13-1.37)^{*}$ \\
\hline Senior high school $(n=22,613)$ & $8,797(38.9)$ & $0.91(0.86-0.96)^{*}$ & $1.17(1.07-1.28)^{*}$ \\
\hline Diploma or higher $(\mathrm{n}=6,373)$ ref & $2,230(35.0)$ & $0.72(0.66-0.78)^{*}$ & \\
\hline \multicolumn{4}{|l|}{ Family economic status } \\
\hline Quintile $1(\mathrm{n}=11,696)$ & $5,013(42.9)$ & $1.12(1.05-1.19)^{*}$ & $1.14(1.05-1.24)^{*}$ \\
\hline Quintile $2(\mathrm{n}=14,022)$ & $5,940(42.4)$ & $1.09(1.03-1.16)^{*}$ & $1.15(1.06-1.24)^{*}$ \\
\hline Quintile $3(n=16,678)$ & $6,947(41.7)$ & $1.06(1.00-1.12)^{*}$ & $1.13(1.05-1.22)^{*}$ \\
\hline Quintile $4(\mathrm{n}=19,558)$ & $7,935(40.6)$ & $1.00(0.95-1.06)$ & $1.13(1.05-1.21)^{*}$ \\
\hline Quintile $5(n=16,046)$ ref & $5,811(36.2)$ & $0.79(0.75-0.84)^{*}$ & \\
\hline \multicolumn{4}{|l|}{ Child's age } \\
\hline$<1$ month $(\mathrm{n}=1,176)$ & $43(3.7)$ & $0.05(0.04-0.08)^{*}$ & $0.06(0.04-0.08)^{*}$ \\
\hline $1-11$ months $(\mathrm{n}=13,820)$ & $5,232(37.9)$ & $0.87(0.82-0.92)^{*}$ & $0.92(0.6-0.98)^{*}$ \\
\hline $12-23$ months $(\mathrm{n}=15,507)$ & $7,013(45.2)$ & $1.27(1.20-1.34)^{*}$ & $1.24(1.17-1.32)^{*}$ \\
\hline $24-35$ months $(\mathrm{n}=15,065)$ & $6,536(43.4)$ & $1.15(1.09-1.22)^{*}$ & $1.16(1.10-1.23)^{*}$ \\
\hline$>35$ months $(\mathrm{n}=32,432)$ ref & $12,823(39.5)$ & $0.93(0.89-0.97)^{*}$ & \\
\hline \multicolumn{4}{|l|}{ Sex } \\
\hline Male $(n=39,559)$ & $16,313(41.2)$ & $1.06(1.01-1.10)^{*}$ & $1.06(1.02-1.11)^{*}$ \\
\hline Female $(\mathrm{n}=38,440)$ ref & $15,333(39.9)$ & & \\
\hline
\end{tabular}

\footnotetext{
${ }^{a}$ OR before calculating other variables with logistic regression tests, ${ }^{*}$ there is a significant difference compared to references

${ }^{b}$ OR after calculating other variables with multiple logistic regression tests, * there are significant differences compared to references
}

The result of the logistic regression analysis in Table 2 shows the relationship between mother and children with ARI. Mother with high CMD has a higher risk of children with ARI 
compared with those mothers with low CMD. After adjusted other variables, the result is same (OR adjusted $=2.12 ; 9.5 \% \mathrm{CI}: 1.87-2.40)$. If considering the maternal age, the analysis result shows that maternal age that has a risk of children with ARI is 16-25 years old compared to those who are older (OR adjusted $=1.30 ; 95 \%$ CI: 1.04-1.64). Maternal education also has a correlation to the risk of children with ARI. The lower the education the mother has, the bigger the risk they have. A similar condition is also shown in the variable of family economic status. The low quintile has the risk of children with ARI compared with the high quintile.

Based on the analysis result in Table 3, it can be stated that CMD experienced by mothers is strongly related to diarrhea suffered by children. If it is compared to mothers with low CMD, than children with high CMD mothers have a higher risk of 2.46\% (95\% CI: 2.03-2.74). Maternal education is related to the risk of having children with diarrhea. If it is compared to a mother who graduated with a diploma 1 or higher, then a mother with no education gets a higher risk of having children with diarrhea history (OR adjusted $=1.75 ; 95 \% \mathrm{CI}$ : 1,48-2.08). A similar risk also occurred in the variable of family economic status. The lower the status, the higher the risk of children suffer diarrhea. The result of the analysis of the children's age states that children aged 12-23 months have the highest risk to suffer diarrhea compared with children aged more than 35 months (OR adjusted $=1.87$; 95\% CI: 1.72-2.04).

Table 3. Relationship of maternal and children characteristics based on diarrhea

\begin{tabular}{|c|c|c|c|}
\hline \multirow{2}{*}{$\begin{array}{c}\text { Maternal and children } \\
\text { characteristics }(N=78,000)\end{array}$} & \multicolumn{3}{|c|}{ Diarrhea } \\
\hline & Prevalence N (\%) & OR $(95 \% \text { CI })^{a}$ & OR $(95 \% \mathrm{CI})^{\mathrm{b}}$ adjusted \\
\hline \multicolumn{4}{|l|}{ Maternal CMD } \\
\hline High CMD $(\geq 7)(n=3,589)$ & $864(24.1)$ & $2.48(2.14-2.87)^{*}$ & $2.36(2.03-2.74)^{*}$ \\
\hline Low CMD $(<7)(\mathrm{n}=74,411)$ ref & $8,433(11.3)$ & & \\
\hline \multicolumn{4}{|l|}{ Maternal age } \\
\hline$<16$ years $(\mathrm{n}=107)$ & $20(18.7)$ & $1.73(0.64-4.68)$ & $1.38(0.51-3.76)$ \\
\hline $16-25$ years $(n=19,280)$ & $2,804(14.5)$ & $1.37(1.27-1.48)^{*}$ & $1.18(0.84-1.65)^{*}$ \\
\hline $26-35$ years $(n=42,585)$ & $4,838(11.4)$ & $0.89(0.83-0.95)^{*}$ & $0.96(0.69-1.34)^{*}$ \\
\hline $36-45$ years $(n=1,297)$ & $1,548(10.1)$ & $0.80(0.74-0.86)^{*}$ & $0.83(0.60-1.16)^{*}$ \\
\hline$>45$ years $(n=731)$ & $87(11.9)$ & $0.99(0.72-1.38)$ & \\
\hline \multicolumn{4}{|l|}{ Maternal education } \\
\hline No education $(\mathrm{n}=7,593)$ & $1,128(14.9)$ & $1.33(1.21-1.47)^{*}$ & $1.75(1.48-2.08)^{*}$ \\
\hline Primary school $(n=22,218)$ & $2,986(13.4)$ & $1.22(1.13-1.31)^{*}$ & $1.61(1.38-1.88)^{*}$ \\
\hline Junior high school $(\mathrm{n}=19,202)$ & $2,452(12.8)$ & $1.11(1.03-1.20)^{*}$ & $1.53(1.31-1.79)^{*}$ \\
\hline Senior high school $(n=22,613)$ & $2,256(10.0)$ & $0.76(0.70-0.83)^{*}$ & $1.25(1.07-1.45)^{*}$ \\
\hline Diploma or higher $(n=6,373)$ ref & $475(7.5)$ & $0.57(0.50-0.66)^{*}$ & \\
\hline \multicolumn{4}{|l|}{ Family economic status } \\
\hline Quintile $1(n=11,696)$ & $1,871(16.0)$ & $1.51(1.38-1.65)^{*}$ & $1.55(1.43-1.68)^{*}$ \\
\hline Quintile $2(n=14,022)$ & $1,713(12.2)$ & $1.04(0.95-1.13)^{*}$ & $1.23(1.13-1.33)^{*}$ \\
\hline Quintile $3(n=16,678)$ & $2,088(12.5)$ & $1.07(0.99-1.17)^{*}$ & $1.20(1.11-1.30)^{*}$ \\
\hline Quintile $4(\mathrm{n}=19,558)$ & $2,108(10.8)$ & $0.86(0.79-0.94)^{*}$ & $1.11(1.03-1.20)^{*}$ \\
\hline Quintile $5(n=16,046)$ ref & $1,515(9.4)$ & $0.73(0.66-0.80)^{*}$ & \\
\hline
\end{tabular}




\begin{tabular}{|c|c|c|c|}
\hline \multirow{2}{*}{$\begin{array}{c}\text { Maternal and children } \\
\text { characteristics }(\mathrm{N}=\mathbf{7 8 , 0 0 0 )}\end{array}$} & \multicolumn{3}{|c|}{ Diarrhea } \\
\hline & Prevalence N (\%) & OR $(95 \% \mathrm{CI})^{\mathrm{a}}$ & OR $(95 \% \text { CI })^{\mathrm{b}}$ adjusted \\
\hline \multicolumn{4}{|l|}{ Child's age } \\
\hline$<1$ month $(\mathrm{n}=1,176)$ & $25(2.1)$ & $0.16(0.09-0.30)^{*}$ & $0.21(0.12-0.38)^{*}$ \\
\hline $1-11$ months $(\mathrm{n}=13,820)$ & $1,641(11.9)$ & $0.99(0.91-1.09)$ & $1.28(1.16-1.42)^{*}$ \\
\hline $12-23$ months $(\mathrm{n}=15,507)$ & $2,572(16.6)$ & $1.65(1.53-1.78)^{*}$ & $1.87(1.72-2.04)^{*}$ \\
\hline $24-35$ months $(\mathrm{n}=15,065)$ & $1,990(13.2)$ & $1.16(1.07-1.25)^{*}$ & $1.45(1.33-1.58)^{*}$ \\
\hline$>35$ months $(\mathrm{n}=32,432)$ ref & $3,068(9.5)$ & $0.66(0.62-0.71)^{*}$ & \\
\hline \multicolumn{4}{|l|}{ Sex } \\
\hline Male $(n=39,559)$ & $4,960(12.5)$ & $1.13(1.06-1.21)^{*}$ & $1.06(1.06-1.21)^{*}$ \\
\hline Female $(n=38,440)$ ref & $4,336(11.3)$ & & \\
\hline
\end{tabular}

The result of the analysis in Table 4 shows the relationship between maternal CMD and characteristics including age, education level, and family economic status. After controlling the variables of education and family economic status, maternal age is significantly related to the maternal CMD. Mother with the highest CMD risk is in $16-25$ years (OR adjusted $=1.98 ; 95 \%$ CI: 1.22-3.23) than 45-year-old mother. The maternal education level is also strongly related to CMD. The lower the education level, the higher the risk that the mother has. The higher risk that is experienced by uneducated mothers with OR adjusted is 3.96\% (95\% CI: 2.77-5.66) than the mother who graduated from Diploma 1 or higher. The variable of family economic status was not related significantly after considering the variables of age and education.

Table 4. Multiple logistic regression analysis between maternal CMD and maternal characteristics

\begin{tabular}{|c|c|c|c|c|}
\hline \multirow[b]{2}{*}{ Factors } & \multicolumn{4}{|c|}{ Estimation of multiple logistic regression } \\
\hline & Coefficient & $\begin{array}{c}\text { Wald } \\
\text { P value }\end{array}$ & $\begin{array}{l}\text { Rasio odds } \\
\text { ( } \geq 7 \text { CMD) }\end{array}$ & $95 \%$ CI \\
\hline Constant & -4.646 & 0.000 & - & - \\
\hline \multicolumn{5}{|l|}{ Maternal age } \\
\hline$<16$ years & 1.040 & 0.320 & 2.829 & $0.364-22.007$ \\
\hline $16-25$ years & 0.687 & 0.006 & 1.988 & $1.223-3.234$ \\
\hline $26-35$ years (reff) & 0.560 & 0.022 & 1.750 & $1.083-2.830$ \\
\hline \multicolumn{5}{|l|}{$>45$ years } \\
\hline \multicolumn{5}{|l|}{ Maternal education } \\
\hline No education & 1.378 & 0.000 & 3.966 & $2.778-5.662$ \\
\hline Primary school & 1.162 & 0.000 & 3.196 & $2.305-4.431$ \\
\hline Junior high school & 1.060 & 0.000 & 2.886 & $2.062-4.037$ \\
\hline Senior high school & 0.767 & 0.000 & 2.153 & $1.561-2.969$ \\
\hline \multicolumn{5}{|c|}{ Diploma 1 or higher (reff) } \\
\hline \multicolumn{5}{|l|}{ Family economic status } \\
\hline Quintile 1 & 0.036 & 0.768 & 1.037 & $0.815-1.320$ \\
\hline Quintile 2 & 0.003 & 0.978 & 1.003 & $0.791-1.273$ \\
\hline Quintile 3 & 0.095 & 0.420 & 1.099 & $0.873-1.384$ \\
\hline Quintile 4 & 0.008 & 0.943 & 1.008 & $0.807-1.260$ \\
\hline Quintile 5 (reff) & & & & \\
\hline
\end{tabular}




\subsection{Discussion}

This study deliberates the relationship between maternal mental health and the history of the illness that children undergo. CMD in the mother is related significantly to the child's illness. After controlling other variables, mothers with CMD have the risk to increase two times of ARI and diarrhea sick scene in children. This result is similar to the research done in Bangladesh and Vietnam stating that children with high maternal CMD have two times the risk of diarrhea compared with children from low CMD mothers [11]. Other meta-analysis results show that babies born to depressed mothers have a higher risk of experiencing diarrhea than babies from non-depressed mothers [13]. Research in Bangladesh concluded that the higher depressive score of mothers and food diffidence problems become the risk factors for diarrhea and respiratory infection in children under two years old [14].

The research on children and mothers who has high emotional status has a high risk of suffering sickness, affected by the household food variables [15]. Cohort research in Ethiopia stated that the symptoms of perinatal CMD increase the risk of diarrhea in infant two times higher than mother without CMD, especially in low-income countries happened during their first 2 months [16]. In this research, there is no correlation between perinatal CMD with ARI or fever after controlling other variables. This condition may happen because the risk of ARI is affected by air pollution, crowd, and maternal health attitude.

Maternal CMD is related to the risks of ARI in a toddler. The result in this research is different from the research done by Rahman et al. Maternal CMD is not related to ARI in infants based on the research done in Pakistan [17]. The different result is done in Nigeria [18]. The research result of the literature review stated that depression in mothers has bad effects on the child's growth, development, attitude, and mental health [19]. Mothers with depressive symptoms have low self-efficacy ability to nurse children suffering from asthma, with several medical procedures. An article by Turney [20] stated that a depressive mother, especially recurrent or chronic depression, place children at adverse health risks when they are five years old after adjusted with mother and child demographic characteristics. Depressive mothers can contribute to the transmission of inequality between generations because poor child health can cause poor health and low economic status in adulthood.

The ability of a mother living in a developing country to give child care so that children can survive and have proper life has a bigger role than the condition in a developed country. This condition is influenced by the more vulnerable environment in a developing country. The problems of poor sanitation, crowd, food insecurity, and sub-optimal maternal care contributed to the higher risk in the child's health [21].

Some literature has proved the correlation between depressions in mothers with child mental health problems and evidently, the maternal psychological condition also influenced child health. The depressive symptoms are prolonged fatigue, difficult concentration, lost interest in doing daily activities that give impact the maternal ability in nurturing and taking care of the children, remember and deal with health problems experienced by children, and comply with medical rules for children who are sick [20].

Maternal CMD is related to age and education. The result is in line with the previous research done in Bangladesh that the factors related to maternal CMD are age and education. Older age and lower education level is significantly related to the maternal CMD condition [22]. The mental health problems not only contributed to the biological factors but also related to the social-economic problems and factors from the environment [23].

The strength of this research is using large data. While the weaknesses are some variables may proceed as cofounder that is not analyzed. The CMD data and sickness child's history are 
taken based on maternal memory, so it may be biased. Another weakness is the method of collecting data using a cross-sectional method, it may not be able to determine the cause-andeffect relationship between maternal CMD and illness child history.

\section{Conclusion}

Maternal CMD is one of the factors related to the sick scene in children. Maternal CMD can increase the risk of ARI and diarrhea in toddlers. It is related to the maternal education level.

\section{Acknowledgement}

The author would like to thank the National Institute of Health Research and Development, Ministry of Health Republic of Indonesia for sharing data.

\section{References}

[1] World Health Organization, "Mental Health Action Plan 2013-2020," Geneva, 2013.

[2] World Health Organization, "Depression and Other Common Mental Disorders: Global Health Estimates," Geneva, 2017.

[3] Badan Penelitian dan Pengembangan Kesehatan, "Litbangkes dalam Angka," Jakarta, 2017.

[4] World Health Organization, "The importance of caregiver-child interactions for the survival and healthy development of young children," Geneva, 2004.

[5] D. Civic and V. Holt, "Maternal depressive symptoms and child behavior problems in a nationally representative normal birthweight sample," Matern. Child Health J., vol. 4, no. 4, pp. 215-21, 2000.

[6] I. Fihrer, C. McMahon, and A. Taylor, "The impact of postnatal and concurrent maternal depression on child behavior during the early school years," J. Affect. Disord., vol. 119, no. 1, pp. 116-23, 2000.

[7] S. H. Goodman, M. H. Rouse, A. M. Connell, M. R. Broth, C. M. Hall, and D. Heyward, "Maternal depression and child psychopathology: a meta-analytic review," Clin. Child Fam. Psychol. Rev., vol. 14, no. 1, pp. 1-27, 2011.

[8] P. Wang, G. A. Morgan, A. Hwang, and L. Chen, "Do maternal interactive behaviors correlate with developmental outcomes and mastery motivation in toddlers with and without motor delay?," Phys. Ther., vol. 94, no. 12, 2014.

[9] T. M. Field, "Early interactions between infants and their postpartum depressed mothers," Infant Behav. Dev., vol. 25, no. 1, pp. 25-29, 2002.

[10] D. A. Adedinsewo, A. S. Fleming, M. Steiner, M. J. Meaney, and A. W. Girard, "Maternal anxiety and breastfeeding: Findings from the MAVAN (Maternal Adversity, Vulnerability and Neurodevelopment) study," J. Hum. Lact., vol. 30, no. 1, pp. 102-109, 2014.

[11] P. H. Nguyen et al., "Maternal mental health is associated with child undernutrition and illness in Bangladesh, Vietnam and Ethiopia," Public Health Nutr., vol. 17, no. 6, pp. 1318-1327, 2014.

[12] L. Liu et al., "Global, regional, and national causes of child mortality: An updated systematic analysis for 2010 with time trends since 2000," Lancet, vol. 379, no. 9832, pp. 2151-2161, 2012.

[13] A. Waqas et al., "Association between maternal depression and risk of infant diarrhea: a systematic review and meta-analysis," Public Health, vol. 159, pp. 78-88, 2018.

[14] M. B. Ullah et al., "Factors associated with diarrhea and acute respiratory infection in children under two years of age in rural Bangladesh," BMC Pediatr., vol. 19, no. 1, pp. 1-11, 2019.

[15] L. C. Anderson, A. Tegegn, F. Tessema, S. Galea, and C. Hadley, "Food insecurity, childhood illness 
and maternal emotional distress in Ethiopia," Public Health Nutr., vol. 15, no. 4, pp. 648-655, 2012.

[16] J. Ross et al., "Perinatal mental distress and infant morbidity in Ethiopia: a cohort study," Arch. Dis. Child. Fetal Neonatal Ed., vol. 96, no. 1, pp. 59-64, 2011.

[17] A. Rahman, J. Bunn, H. Lovel, and F. Creed, "Maternal depression increases infant risk of diarrhoeal illness: A cohort study," Arch. Dis. Child., vol. 92, no. 1, pp. 24-28, 2007.

[18] A. O. Adewuya, B. O. Ola, O. O. Aloba, B. M. Mapayi, and J. A. O. Okeniyi, "Impact of postnatal depression on infants' growth in Nigeria," J. Affect. Disord., vol. 108, no. 1-2, pp. 191-193, 2008.

[19] L. Pak and P. J. Allen, "The impact of maternal depression on children with asthma," Pediatr. Nurs., vol. 38, no. 1, pp. 11-20, 2012.

[20] K. Turney, "Maternal depression and childhood health inequalities," J. Health Soc. Behav., vol. 52, no. 3, pp. 314-332, 2011.

[21] A. Rahman, R. Harrington, and J. Bunn, "Can maternal depression increase infant risk of illness and growth impairment in developing countries?," Child. Care. Health Dev., vol. 28, no. 1, pp. 51-56, 2002.

[22] A. M. Khan and M. S. Flora, "Maternal common mental disorders and associated factors: a crosssectional study in an urban slum area of Dhaka, Bangladesh," Int. J. Ment. Health Syst., vol. 11, no. 1, pp. 1-8, 2017.

[23] World Health Organization, "Mental health: strengthening our response," 2018. [Online]. Available: http://www.who.int/mediacentre/factsheets/fs220/en/. 